\title{
Life Design Counseling outcome and process: A case study with an adolescent
}

\author{
Paulo Cardoso ${ }^{\mathrm{a}, *}$, Miguel M. Gonçalves ${ }^{\mathrm{b}}$, Maria Eduarda Duarte ${ }^{\mathrm{c}}$, Joana R. Silva ${ }^{\mathrm{b}}$, Daniela Alves ${ }^{\mathrm{b}}$ \\ a Department of Psychology, University of Évora, Portugal \\ b School of Psychology, University of Minho, Portugal \\ c Faculty of Psychology, University of Lisbon, Portugal
}

\section{A R T I C L E I N F O}

\section{Article history:}

Received 20 November 2015

Received in revised form 7 January 2016

Accepted 8 January 2016

Available online 11 January 2016

\section{Keywords:}

Life Design Counseling

Innovative moments

Process of change

Adolescence

\begin{abstract}
A B S T R A C T
This article aims to explore the relationship between clients' narrative transformation and the promotion of vocational decidedness and career maturity in a mid-adolescent case of Life Design Counseling (LDC). To assess LDC outcomes the Vocational Certainty Scale and the Career Maturity Inventory - Form $C$ were used before and after the intervention. To intensively analyze the process of LDC change two measures of narrative change were used: the Innovative Moments Coding System (IMCS), as a measure of innovation emergence, and the Return to the Problem Coding System (RPCS), as a measure of ambivalence towards change. The results show that the three LDC sessions produced a significant change in vocational certainty but not in career maturity. Findings confirm that the process of change, according to the IMCS, is similar to the one observed in previous studies with adults. Implications for future research and practice are discussed.
\end{abstract}

(c) 2016 Elsevier Inc. All rights reserved.

Life Design Counseling (LDC; Savickas, 2011a) is an approach to career counseling that supports clients in constructing a narrative of their past, present and future by providing a sense of continuity and coherence. In other words, it intends to facilitate the development of a narrative identity (McAdams, 1993). In this approach, career plans are integrated into the individual's psychosocial dynamics to become one of the dimensions in which the self is projected into the future.

Studies with adults receiving individual (Refhuss, Del Corso, Glavin, \& Wykes, 2011) and group counseling (Di Fabio \& Maree, 2011) have supported LDC's efficacy. In recent studies, an intensive analysis of the cases of a young adult (Cardoso, Silva, Gonçalves, \& Duarte, 2014a) and an adult (Cardoso, Silva, Gonçalves, \& Duarte, 2014b), using the Innovative Moments Model (IMM; Gonçalves, Matos, \& Santos, 2009) illustrated the patterns of change promoted by LDC.

However, one may question whether the pattern of change in adolescents is similar to the one found in adults, as the capacity to elaborate mature autobiographic thought is gradually developed during adolescence (Habermas \& Bluck, 2000; McAdams, 1985). The emergence of internal resources during this life period, such as cognitive abilities, contribute to this process by facilitating the awareness of causal links between biographical events and self and personal development, the ability to construct interconnected and globally coherent life narratives and the acquisition of cultural knowledge about normative aspects of life (Habermas, Ehlert-Lerche, \& de Silveira, 2009). On the other hand, external factors, such as confronting developmental tasks (e.g., the need to commit to educational and vocational pursuits) motivate the construction of a global and coherent life story (Erikson, 1968; Havighurst, 1948).

Understanding the types of narrative elaboration that LDC can promote in adolescents may help practitioners adjust their interventions to clients' capacities and strengthen and enhance our knowledge of the process of change in LDC. Therefore, similar to

\footnotetext{
* Corresponding author at: Departamento de Psicologia, Universidade de Évora, Apartado 94, 7002-554, Lisboa, Portugal.

E-mail address: pmsc@uevora.pt (P. Cardoso).
} 
previous studies (Cardoso et al., 2014a, 2014b), we have employed the IMM (Gonçalves et al., 2009) to analyze the patterns of change promoted by LDC in the case of a mid-adolescent female. The current study expands upon previous studies and evaluates not only the process but the efficacy of the intervention as well.

\section{Life Design Counseling}

Within the epistemological framework of social constructionism, LDC is an application of the Career Construction Theory (CCT; Savickas, 2013) to career counseling. With the goal of facilitating the construction of career plans through re-authoring narrative identity, the intervention begins with an exploration of the client's life story using the Career Construction Interview (CCI; Savickas, 2011a), which is a semi-structured interview in which a practitioner inquires about five topics that form life themes and can inform decision-making about the current transition. The topics are: (1) role models for self-construction; (2) magazines, television shows or websites for manifest interests, (3) a favorite story from a book or movie for creation of the script of the next episode; (4) sayings or mottos for advice to self; and (5) early recollections for perspective on the present problem or transition. In the second session, the counselor helps the client construct a narrative that creates coherence to the life episodes previously identified. In a meaning co-construction process, the client is helped to identify a life theme, namely the core problem in his or her life and the solutions he or she has sought to solve it (Csikszetmihalyi \& Beattie, 1979). The understanding of this thematic core is essential in enabling the client to construct a self-narrative endowed with continuity and coherence (Savickas, 2011a). As life themes in the vocational domain are expressed in relationships between needs, interests, and goals, the counselor's task is to support the client in elaborating on the episodes of his or her life story to create an understanding of the role of precociously structured needs (past) in the definition of goals and plans (future) that allow for the fulfillment of those needs. Clients are also helped to understand how their interests (present) are instrumental to the achievement of goals and, consequently, the fulfillment of needs (Savickas, 1995).

Finally, the third session of the intervention is focused on the establishment of connections between life themes and career plans. The construction of realistic plans, that are not limited to the role of worker, is facilitated. In this manner, more than a simple career plan is developed; the client constructs a true life project, as one may project solutions for the global theme or themes of one's life in several career roles (Savickas, 2013).

Throughout the three sessions the counselor provides a secure space in which clients are supported in the analysis of their subjective experience both to construct new meanings about themselves and to build new career intentions (Savickas, 2015).

Table 1

Examples of innovative moments regarding a dominant self-narrative underlying career decision-making problem of "valuing others". Adapted from Gonçalves, Ribeiro, Mendes, et al., 2011.

\begin{tabular}{|c|c|c|c|}
\hline Types of IM & Subtypes & Definition & $\begin{array}{l}\text { Examples } \\
\text { (Problematic narrative: valuing others) }\end{array}$ \\
\hline \multirow[t]{4}{*}{$\begin{array}{l}\text { Low level IMs } \\
\text { (creating distance from the problem) }\end{array}$} & Action I & $\begin{array}{l}\text { Performed and intended actions } \\
\text { to overcome the problem }\end{array}$ & $\begin{array}{l}\text { C: You know, I'm calling companies and } \\
\text { sending my resume and all of that stuff. }\end{array}$ \\
\hline & Reflection I & New understandings of the problem & $\begin{array}{l}\text { C: I have all of these ideals and values that I } \\
\text { like, and it's a matter of just bringing them } \\
\text { and then making sure I incorporate them } \\
\text { into my life. }\end{array}$ \\
\hline & Protest I & $\begin{array}{l}\text { Objecting to the problem and its } \\
\text { assumptions }\end{array}$ & $\begin{array}{l}\text { C: Right. I'm getting tired of that. } \\
\text { T: And you're getting tired of it, and it's not } \\
\text { an intriguing game; it's time for a new } \\
\text { game. }\end{array}$ \\
\hline & & & $\begin{array}{l}\text { C: That game sucks. Time to move on to the } \\
\text { next game. Right. I'm getting tired of that. }\end{array}$ \\
\hline \multirow[t]{4}{*}{ High Level IMs (centered on change) } & $\begin{array}{l}\text { Performing change } \\
\text { (Action II) }\end{array}$ & $\begin{array}{l}\text { Generalization into the future and other } \\
\text { life dimensions of good outcomes } \\
\text { (performed or projected actions) }\end{array}$ & $\begin{array}{l}\text { C: Yes, yes. I am starting to see that I can't } \\
\text { forget about myself, not only at work but } \\
\text { also in other dimensions of my own life. } \\
\text { Before I just tried to answer to everybody's } \\
\text { needs, but now I am making time to do } \\
\text { things that I really enjoy, that actually make } \\
\text { me feel alive. }\end{array}$ \\
\hline & Reflection II & $\begin{array}{l}\text { Contrasting Self (what changed?) } \\
\text { OR } \\
\text { Self-Transformation process (how/why } \\
\text { change occurred) }\end{array}$ & $\begin{array}{l}\text { C: That's why I'm so easy, you know, more } \\
\text { comfortable with you telling you all these } \\
\text { things versus if I was to tell my parents or } \\
\text { tell my friends ( } \ldots \text { ) }\end{array}$ \\
\hline & Protest II & Assertiveness and empowerment & C: Why would I bother? That's my life \\
\hline & Re-conceptualization & $\begin{array}{l}\text { Moments distanced from the experience } \\
\text { (meta-positions) where the self is } \\
\text { repositioned outside the problematic } \\
\text { experience AND also understands the } \\
\text { processes involved in this transformation }\end{array}$ & $\begin{array}{l}\text { C: Not knowing which direction to take, } \\
\text { or which decisions and choices to make to } \\
\text { find myself... It made me feel confused, } \\
\text { without peace. Now it's different. To know } \\
\text { where we are, what we want and the career } \\
\text { we want to embrace gives us peace and } \\
\text { tranquility. }\end{array}$ \\
\hline
\end{tabular}




\section{Change in career counseling from the perspective of the Innovative Moments Model}

From the social constructionism perspective, change is a meaning construction process occurring within a matrix of interpersonal relationships (Cardoso, 2012; Gonçalves, 2000). These meanings are structured by the narrative thought mode (Bruner, 1986; McAdams, 1993; Sarbin, 1986; White \& Epston, 1990). Still within this epistemological framework, the innovative moments' perspective (Gonçalves et al., 2009) provides an explanation of narrative transformation in psychotherapy based on two premises. The first is that narrative construction involves a dialogic process of negotiation, tension, discord and alliance among different self-positions or internal voices (Hermans \& Hermans-Jansen, 1995). The second is that psychological suffering results from problematic self-narratives (Gonçalves et al., 2009) in which the diversity of positions within the self are seriously constrained. In this framework, change occurs when the client challenges the problematic self-narrative and thus introduces novelty into his or her habitual, but maladaptive, mode of behaving, thinking, or feeling. These moments are called innovative moments (IMs; Gonçalves et al., 2009; Gonçalves, Ribeiro, Mendes, Matos and Santos, 2011; White \& Epston, 1990). A considerable amount of research has validated the importance of IMs in the process of therapeutic change for different clinical approaches and different types of problems (Alves, Mendes, Gonçalves, \& Neimeyer, 2012; Gonçalves et al., 2012; Gonçalves, Mendes, Ribeiro, Angus, \& Greenberg, 2010; Matos, Santos, Gonçalves, \& Martins, 2009; Mendes et al., 2011; Ribeiro et al., 2014; Santos, Gonçalves, \& Matos, 2011).

Both hypotheses-testing (Gonçalves et al., 2012; Matos et al., 2009; Mendes et al., 2011) and case studies (Alves et al., 2012; Gonçalves et al., 2010; Santos et al., 2011) have yielded support for a categorization of IMs into seven different types (3 low level and 4 high level IMs). The low level IMs allow individuals to distance from the problem through the performance of actions and specific behaviors against the problem (action I), new understanding that makes the problem illegitimate (reflection I) and positions of critique in relation to the problem or/and the others who support it (protest I). On the other hand, high level IMs refer too narrative elaborations focused on the process of change, such as references to strategies implemented to overcome the problem (reflection II), to of new positions expressing assertiveness and empowerment (protest II), to change and the processes underlying the change (reconceptualization) and, to new aims or projects, as consequence of change (performing change). Table 1 contains a description and specific examples of these IMs.

Research has shown that the emergence of IMs, as well as the therapeutic process, follows a pattern characterized by low level IMs appearing in the early stages of the intervention. As therapy proceeds to intermediate stages, high level IMs and particularly reconceptualization IMs begin to emerge. Reconceptualization IMs are central to sustaining change because they provide coherence to the emerging, new position of the self while placing the client as an agent of his or her own change (for a more indepth presentation of the role of reconceptualization in change, see Gonçalves \& Ribeiro, 2012). In the latter part of the intervention, performing change IMs emerge when the client mentions new aims or plans as a consequence of change.

Research on the process of change in LDC (Cardoso et al., 2014a, 2014b) has revealed similarities with the patterns of change in psychotherapy, namely the gradual increase in the proportion of IMs across the sessions, which is an evolution initially characterized by action I, reflection I and protest I and allowing the client to create distance from the problem. Thus, innovations are more focused on the comprehension of the problem and intentions to cope with the problem at the beginning of the process. Gradually, reflection II and protest II IMs emerge, representing elaborations of how change has been developing as new selfrepresentation and references to alternative career plans arise. This pattern is also observed in the initial stages of psychotherapeutic interventions (Mendes et al., 2011).

However, contrary to what has occurred in psychotherapy, reconceptualization IMs have not emerged throughout LDC sessions (Cardoso et al., 2014a, 2014b). We proposed two hypotheses to explain their absence. First, as opposed to what occurs in psychotherapy, the change process in LDC does not elicit these moments. This hypothesis is consistent with the studies developed on "spontaneous" or daily change with the IMM. In a previous study (Meira, Gonçalves, Salgado, \& Cunha, 2009) on daily change, the participants only produced reconceptualization IMs when they were explicitly invited to elaborate on the change process. Curiously, only participants that changed significantly were able to produce reconceptualization IMs in response to the interviewer's invitation. Future studies with LDC may reproduce this design by inviting clients to elaborate on their change process, thus testing if reconceptualization emerges in changed clients but not in unchanged ones. A second possibility is that only three sessions of counseling are insufficient to produce reconceptualization IMs, as this type of IM usually emerges in the middle of the psychotherapeutic process. In this case, even if prompted by the counselor, clients should be unable to elaborate reconceptualization IMs, independent of the change status. Future research should address these hypotheses.

\section{Ambivalence from the perspective of innovative moments}

From the IMM perspective, change is not linear, as clients often have to address ambivalence towards changing (see also Westra, 2011). Ambivalence is seen as an expression of the dynamics of the self, and it tends to occur in cycles throughout the intervention. At the beginning of treatment, the problematic self-narrative blocks the emergence of narrative novelties and consequently suppresses manifestations of discontinuity and inconsistency in the self (Ribeiro, Gonçalves, Silva, Brás, \& Sousa, 2015). As IMs start to emerge, a discontinuity within the self also emerges, as the previous problematic self-narrative no longer excludes alternative meanings. Ambivalence is revealed in therapeutic dialog when, after the elaboration of IMs, the client reemphasizes again the problematic self-narrative. These expressions of ambivalence are empirically identified as return to the problem markers (RPM), which are moments of trivialization, negation, or contradiction of the previous emergent IM (e.g., "I feel more confident [reflection I IM], but I'm not sure I'm going to make it" [RPM]). 
As with IMs, research has found that ambivalence evolves differently with successful and unsuccessful cases. In unsuccessful cases, ambivalence markers (i.e., RPMs) tend to appear throughout therapy (Gonçalves, Ribeiro, Stiles, Conde, Matos, Martins, et al., 2011) and do not decrease throughout treatment (or can even increase in some cases), demonstrating that ambivalence persists as a frequent phenomenon when it is not successfully solved.

Ambivalence was also present in the two case studies on narrative change in LDC. However, in the case without a dominant problematic self-narrative underlying the career problem, ambivalence was residual (Cardoso et al., 2014b), whereas it was not residual in the other case in which the career problem was accompanied by a problematic self-narrative saturated with themes of sadness and insecurity (Cardoso et al., 2014a). This difference suggests that ambivalence is more likely to occur in cases in which vocational difficulties are associated with other psychological difficulties and less likely to occur when these complicating problems are not present. This hypothesis requires further studies.

\subsection{Purpose of the present study}

Two main questions guided this study on the process and outcome of face-to-face LDC in a case of an adolescent receiving LDC: (1) From the perspective of the IMs model of change, how does LDC promote meaning transformation in an adolescent? and (2) Is LDC effective in the promotion of vocational certainty and career maturity?

In previous studies, the same counselor implemented the intervention with two young adults, a college student and a carpentry apprentice (Cardoso et al., 2014a, 2014b). In the current case, a different counselor worked with an adolescent at the end of her secondary studies, therefore at a different stage of her psychosocial and career development. By employing a different counselor and a client in a distinct developmental stage, the current case study replicates and broadens our knowledge on the process of change in LDC. Moreover, outcome assessment was conducted through follow-up information in only one of the previous studies, and it was obtained four weeks after the intervention (Cardoso et al., 2014a). In this study, measures of career choice certainty and career maturity were administered one week before the beginning of the study and again one week after the end of the intervention. These measures evaluate intentionality and career adaptability, respectively, which are two goals of LDC interventions (Savickas, 2015). The use of these measures is also a response to the call made by Brown (2015) for researchers to attend to issues of clinical or practical significance in the design of career intervention efficacy and effectiveness studies.

\section{Method}

\subsection{Participant}

The 16-year-old client had completed 11th grade in the Portuguese secondary school system and requested help in deciding on a higher education program, which occurs after the final year of secondary education (12th grade). However, in the first session she revealed a number of career problems: (a) indecisiveness and insecurity in the choice of a higher education program (e.g., "I'm not sure what to... what to choose in college. I don't know which... I'm afraid I might choose a program and then it's not... not at all what I want to do"), (b) inadequate career exploration attitudes (e.g., "Where does a marine biologist work? Maybe in laboratories or even kind of... I don't know, at sea, or exploring, and they can be teachers"), and (c) interest dispersion (e.g., "Working in laboratories, doing research, exploring... Early childhood educator, that's one thing I've always liked. I am working there... helping people, like in the field of music, as an intern, helping certain people as an assistant and... photography...).

Informed consent was obtained from the participant and from her parents and all three counseling sessions were videorecorded and transcribed by a master student in psychology for intensive analysis with the Innovative Moments Coding System (IMCS; Gonçalves, Ribeiro, Mendes, et al., 2011) and the Return to the Problem Markers Coding System (RPMCS; Gonçalves, Ribeiro, Stiles, et al., 2011).

\subsection{Counselor}

The counselor was a female educational psychologist with a Master's degree in Vocational Psychology, during which she had training on LDC. In addition, she had over 10 years of experience working in a school context in which career counseling was one of the intervention areas.

\subsection{Researchers}

The evaluators involved in the data analysis process were two post-doctoral researchers who were members of the research team and analyzed the process of change in psychotherapy using the IMCS and the RPMCS. These coders were trained and reliable coders on the IMCS.

\subsection{Measures}

To evaluate the results of the intervention, the following measures were administered one week before the beginning of the study and again one week after the end of the intervention. 
4.4.1. The Vocational Certainty Scale (VCS; Santos, 2007)

The VCS is composed of four items (e.g., "I have chosen a career that I do not intend to change") that are responded to on a 6-point Likert scale ( 1 = disagree entirely; 6 = agree entirely), with higher scores indicating a higher level of vocational certainty. The score reliability (Cronbach's alpha) was found to be good in a sample of Portuguese secondary school students (.85; Santos, 2007).

\subsubsection{The Career Maturity Inventory - Form C (CMI; Savickas E Porfeli, 2011), Portuguese version (Janeiro E Marques, 2010)}

This form assesses career maturity among high school students using four scales of six items each: the Concern scale, which assesses orientation to and involvement with the process of career decision-making; the Curiosity scale, which assesses exploration of the labor world and the seeking of information regarding occupations and their requirements; the Confidence scale, which assesses self-efficacy for making wise and realistic career choices; and the Consultation scale, which assesses the extent to which the individual seeks advice from others in making career and occupational decisions. In the Portuguese version of the CMI (Janeiro, Mota, \& Ribas, 2014), the reliability (Cronbach's alpha) of the individual scales was .62 for the Concern scale, .74 for the Curiosity scale, .78 for the Confidence scale, and .69 for the Consultation scale. The Consultation scale was not included in the total score of career maturity, because the interpretation of its scores depends on cultural conceptions of how to make adaptive career choices. For example, in a more interdependent culture, low scores do not reflect low career maturity, since seeking assistance in career decision making or advice from others is a common practice (Savickas \& Porfeli, 2011). Thus, the alpha coefficient for the total score, based on 18 items, was .86 .

The exploration of the intervention process was conducted through an intensive analysis of the transcripts of LDC sessions, employing two qualitative analysis systems.

\subsubsection{Innovative Moments Coding System (IMCS; Gonçalves, Ribeiro, Mendes, Matos, et al., 2011)}

The IMCS analyzes moments in the dialog in which the client produces novelties regarding his or her usual ways of behaving, thinking or feeling. The IMCS has proved to be a reliable and systematic method of studying the process of change in brief psychotherapy. It has shown good reliability across therapeutic models and diagnoses. The average percentage of agreement has ranged from $84 \%$ to $94 \%$ in the identification of IMs in transcripts, and the average Cohen's Kappa has ranged from .80 to .97 in the classification of IMs into types (Gonçalves, Ribeiro, Mendes, et al., 2011). The findings of these studies also support the criteria, convergent and divergent validity of the IMCS (Gonçalves, Ribeiro, Mendes, et al., 2011). For example, the empirical data from these studies suggest that there is a significantly higher elaboration of IMs in good than in poor outcome cases (Gonçalves et al., 2010; Matos et al., 2009; Mendes et al., 2010). Furthermore, a pattern of IM changes systematically emerged in these studies, in which reconceptualization clearly discriminates good from poor outcome cases. Finally, more recent studies (e.g. Gonçalves, Ribeiro, Silva, Mendes \& Sousa, in press) suggest that the elaboration of specific IMs (reconceptualization) in one session is predictive of symptom improvement in the following one.

\subsubsection{Return to Problem Coding System (RPCS; Gonçalves, Ribeiro, Stiles, et al., 2011)}

The RPCS identifies moments in the discourse in which the client, after producing an IM, immediately returns to and emphasizes the problematic self-narrative again (i.e., produces a RPM), thus attenuating the meaning of the IM. RPMs are only coded if they emerge in the same speech turn of an IM (or are the first utterance of the client after a speech turn by the therapist following the occurrence of an IM). Examples of RPMs identified in such cases are provided in the results section.

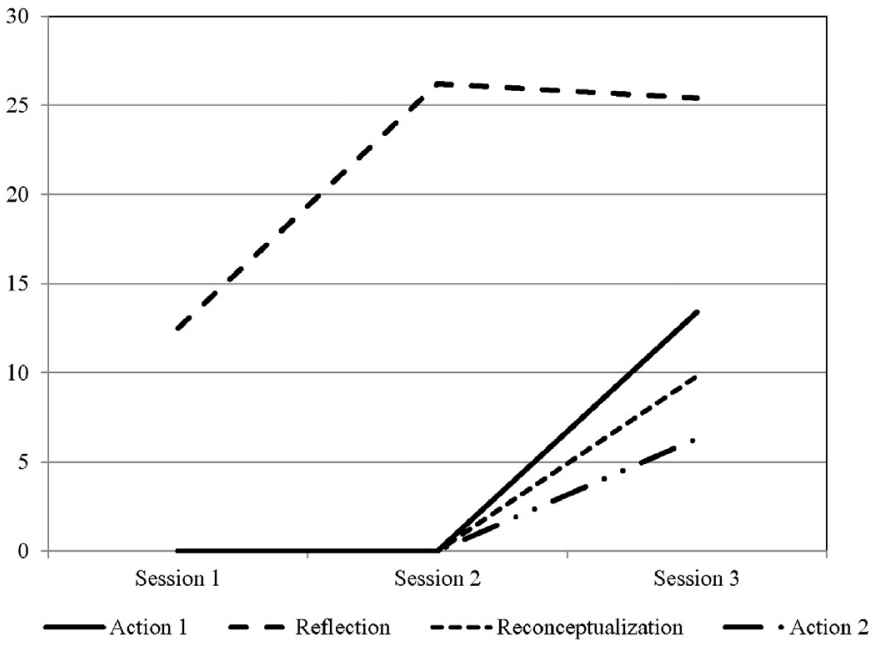

Fig. 1. Evolution of innovative moments throughout the career counseling process. 


\subsection{Procedures}

Two coders who are experienced in the two coding systems began by consensually defining a list of the client's problems (the facets of the problematic self-narrative). Referring to this list, the coders then identified references to thoughts, feelings or actions that defied the problematic self-narrative. Next, they decided on the type of IM and its extension on the transcripts. After completing independent coding of all of the sessions, the coders resolved their coding disagreements to obtain a final version of the IM codes. All of the sessions were coded in their chronological order (i.e., session 1, session 2, session 3). The proportion of IMs was calculated by considering the proportion of words involved in the IMs within the total number of words in the session. This enabled the calculation of the proportion of IMs for each session and for the three sessions overall. Research on change from the IM perspective has shown that the proportion of words involved in narrative elaboration is a more reliable indicator of IMs than their frequency alone (Gonçalves, Ribeiro, Mendes, Matos, et al., 2011). After the coding of IMs, the coding of RPMs was conducted. This process led to the percentage of IMs that were attenuated by a RPM. Thus, the percentage of RPMs could be calculated for each session.

Coding reliability was assessed by calculating the percentage of agreement on IMs (i.e., the proportion of the transcripts that were considered to be IMs by both coders) and the Cohen's Kappa for type of IMs and presence of RPMs. The percentage of agreement was $87 \%$, which indicates that both coders agreed that $87 \%$ of the text constituted an IM, independent of the type. The Cohen's Kappa was .85 for the type of IM and .84 for RPMs. These measures indicated that a good agreement between coders was achieved (both above the value of .75, as suggested by Hill \& Lambert, 2004).

\section{Results}

\subsection{Narrative transformation}

\subsubsection{Types of IMs in the career counseling process}

IMs occurred in 9.3\% of the overall transcript from the 3 sessions. A progressive increase in the proportion of IMs was visible from session one to session three: $4.9 \%, 7.7 \%$ and $15.3 \%$, respectively. As shown in Fig. 1, throughout the entire LDC process, reflection IMs were the type of IM with the highest proportion (20.7\%), followed by action I (4.2\%), action II (1.9\%), and reconceptualization (1.1\%).

A more detailed analysis of the evolution of reflection IMs throughout the three sessions revealed that the proportion of reflection I IMs increased from the first to the second session from $9.8 \%$ to $25.4 \%$ and then decreased in the third session (12.8\%). In contrast, reflection II IMs had a proportion of $2.7 \%$ in the first session and $0.9 \%$ in the second session and then rose to $12.6 \%$ in the third. In the first session, the reflection I IMs appeared as adaptive thoughts expressing interests (e.g., "Marine Biology, which is something I like a lot"). In the second session, the expression of interests emerged linked to the expression of needs (e.g., "I liked, for instance, Biology and such... I would like to be like my role models, who are persistent and follow their dreams"). By the middle of the second session, reflection II IMs began to emerge, with the client elaborating on vocational alternatives that were adjusted to her interests, employing Holland's (1997) interest typology (e.g., "So, Theater is A-R-E, Advertising Photographer is A-I-R, Music Teacher is A-S-E"). In the third session, the proportion of reflection Is was reduced and the proportion of reflection IIs increased, relative to the second session. This suggests that although the client still expressed adaptive thoughts (e.g., "Let it be my way. I like, maybe I like to work alone, so as not to have people interfering..."), in the third session, expressions of the new identity representation (e.g., "I don't see myself doing a lot of engineering work, although afterwards I could do several different things, but... I stayed more... with Biology"), references to vocational priorities (e.g., "Geology I also liked, but it was more generally like Biology") and new forms of defining her priorities also emerged (e.g., "But then I saw that thing with Marine Biology, I didn't know what the average was or anything, so I went and checked, and I saw kind of... there were very low grades of the last people that got in").

Action I IMs only occurred in the third session (13.4\%), when the client elaborated on exploratory activities that were related to the vocational alternatives constructed in the previous session (e.g., "I've checked that first website, I think it was the one on access to higher education. I've been looking into what areas I would like to follow in college").

Performing change (Action II) IMs also occurred in the third session (6.3\%), when the client referred to new plans stemming from the definition of vocational goals. For example, she mentioned the intention of studying abroad (e.g., "It was... something I always wanted, to study abroad... An experience for a few months, to stay there for a few months, even if I had to work").

Finally, reconceptualization occurred at the end of the third session, with a proportion of $9.8 \%$, when the counselor explored the benefits of the intervention for the client. The client referred to the contribution of the intervention in consolidating her career plans and the role of career exploration in eliciting change: "I knew before that I wanted something related to Biology, but I had not searched. I knew it was more Biology because I liked the area more. Because it was something that I really wanted to do, but now I actually like it, I have been looking into jobs, those that Marine Biology leads to, and one of them was working at a zoo."

\subsubsection{Ambivalence in the career counseling process}

The assessment of RPMs showed a reduced ambivalence throughout the intervention. Of the total IMs, only $1.9 \%$ were attenuated by RPMs. Per session, ambivalence occurred in $2.2 \%, 1.2 \%$ and $2.3 \%$ of the IMs, respectively. 


\subsection{Vocational certainty and career maturity evolution}

To assess vocational and career maturity evolution throughout the three LDC sessions, we employed the Reliable Change Index $(\mathrm{RCI}>1.96)$, established by Jacobson and Truax (1991), and the $\mathrm{z}_{\mathrm{cs}}$ score proposed by Brown (2015), an index that creates an "estimate of [the] client's resemblance to the typical or average person in a comparison or norm group chosen to demonstrate the practical or clinical impact of an intervention" (p. 66). Because ours is a case study, both criteria were calculated for each variable from the mean and standard deviation of the VCS (Santos, 2007; $M=17.19 ; S D=5.05$ ) and the CMI (Janeiro et al., 2014; $M=10.9 ; S D=3.6$ ) in normative Portuguese samples of non-clients. The client's raw VCS scores progressed from 9 to 19 , yielding an $\mathrm{RCI}=3.62$ and thus revealing a significant change in vocational certainty. This result was confirmed by the evolution in the client's $z_{\mathrm{cs}}$ score, which showed that the participant moved from -1.6 standard score below the norm group mean pre-intervention to a +2.8 standard score post-intervention. These results indicate a development from a negative to a positive perception of vocational certainty. The global CMI raw scores showed a slight progression, from 10 to 11 , which was a small and non-significant change $\left(\mathrm{RCI}=.32 ; \mathrm{z}_{\mathrm{cs}}=-.25\right.$ pre-intervention and $\mathrm{z}_{\mathrm{cs}}=.03$ post-intervention $)$.

\section{Discussion}

This study replicates previous ones (Cardoso et al., 2014a, 2014b) by analyzing patterns of narrative innovation and ambivalence in LDC. The results confirm a process of change similar to those found in previous studies (Cardoso et al., 2014a, 2014b). Namely, a gradual increase in the proportion of innovative conversation was found in a pattern similar to that observed in psychotherapy (Alves et al., 2012; Matos et al., 2009; Mendes et al., 2010), which suggests that the accumulation of IMs and a specific pattern of emergence (mainly constituted by high level IMs) may lead to the transformation of a client's self-narrative (Gonçalves \& Ribeiro, 2012). This process across the three sessions was characterized by cycles of action and reflection, which are also observed in the initial stages of psychotherapeutic interventions (Mendes et al., 2011). Reflection was the predominant type of narrative elaboration. Its evolution throughout the sessions indicated that, initially, the client deepened her understanding of the problem. Next, she transitioned into expressing her intention of solving the problem and into new formulations of the problem (reflection I). Illustrative of this transformation was the emergence of the expression of interests with the expression of needs. Finally, the reflection IMs became expressions of the new self-representation (reflection II). Action IMs occurred complementarily in the third session as a consequence of the client's evolution; references to new plans stemming from the definition of vocational goals were accompanied by references to exploratory activity to implement such plans.

The narrative transformation described above follows the goals of the successive sessions. The change process, beginning with the understanding of the problem, the identification of life themes and the emergence of a new self-representation, matched the goals of the first two sessions, which focus on the definition of the problem, the exploration of the life story and the construction of a new narrative that is enhanced with coherence and continuity. In a later phase, the change in the client was completed with more frequent expressions of well-being and with references to new career plans and behaviors to implement them. This latter evolution matches the goals of the last session, which are focused on supporting the formulation of realistic plans based on the reorganization of the narrative identity. These findings regarding the pattern of narrative innovation evolution are consistent with research showing that clients perceive LDC as a practice benefiting awareness, self-discovery, sense of connection and direction. The consistency of these results (Cardoso et al., 2014a, 2014b; Refhuss et al., 2011) is a contribution to its generalizability.

Reconceptualization IMs occurred in the third session when the counselor invited the client to contemplate how she had changed throughout the sessions. The fact that the non-spontaneous emergence of this type of IM did not preclude significant changes in the levels of vocational certainty strengthens the possibility that reconceptualization is not a necessary condition for change in career counseling, as previously suggested (Cardoso et al., 2014a, 2014b). As reconceptualization facilitates the coherence and continuity of the self-narrative, the progressive identification of the individual with a new self-narrative, and the resolution of ambivalence (Gonçalves \& Ribeiro, 2012), it is possible that reconceptualization may be necessary to sustain change in cases in which career problems have highly dominant underlying problematic self-narratives. Alternatively, reconceptualization may emerge later as the results of the changes that occurred in the counseling process are expanded and consolidated. In fact, in a previous study (Cardoso, 2012) with a follow-up of 10 months, reconceptualization emerged as the client used the knowledge of the change process (part of the reconceptualization IM) to help maintain his gains in daily life.

Similar to previous case studies, ambivalence was present in the client's speech. It is interesting, however, that ambivalence was residual in this case and a previous one in which the career problem did not have an underlying dominant problematic self-narrative (Cardoso et al., 2014b), whereas it was significant in another case in which the career problem was accompanied by a problematic self-narrative saturated with themes of sadness and insecurity (Cardoso et al., 2014a). This difference supports the idea that greater ambivalence may result from the dominant problematic self-narrative exerting a greater opposition to narrative innovation when compared with cases that do not have complicating psychological difficulties. This idea is also supported by research in career counseling, which shows that interventions addressing complex career problems should be conducted for a longer period of time (Heppner \& Hendricks, 1995; Stauffer, Perdrix, Masdonati, Massoudi, \& Rossier, 2013).

The use of outcome measures before and after the intervention demonstrated that the patterns of narrative innovation were related to a significant change in vocational certainty but not in career maturity. Regarding vocational certainty, this result may be explained by the focus of the intervention on the client's complaint, namely the greater focus on the resolution of the vocational indecision than on the promotion of career maturity. The non-significant effect of the intervention on career maturity may be due to a combination of factors. One of these factors may have been the low adaptive readiness (Savickas, 2013) the client showed 
throughout the sessions. In the first session, when the counselor encouraged the exploration of educational and vocational opportunities, the client's response was: "but that is something I don't have much patience for either." In the second session, the encouragement was repeated, to which the client again said: "I don't have the patience to search for programs, it's a lot of work". In the third session, the career exploration was still futile: "I checked which programs I might like to follow in college. I didn't look into many, and everything that I looked into was more... everything was related to the same thing." The client's low adaptive readiness may be due to the client still having one year to decide which programs to apply to. In fact, the literature on career development shows that the arrival of moments of decision tends to activate exploratory behavior (Gottfredson, 2002). Therefore, it is possible that the main goal of the client was to clarify her vocational identity by defining her career plans, with less emphasis on the development of attitudes and behaviors that might facilitate the implementation of career plans. The second possible reason for the modest increase in career maturity may have been the nature of the career maturity construct itself. According to the integrative perspective on personality (McAdams \& Pals, 2006), career maturity is included within adaptation processes (Savickas, 2013), and its development involves the acquisition of attitudes, skills and knowledge (Savickas, 2013), which research has shown to be the most difficult to change in career counseling (Whiston \& Rose, 2015). It is thus possible that the three LDC sessions, which mostly focused on the client's complaint, may have been insufficient to produce significant changes in her career maturity. The third possible explanation emerges from the previous one, that is, this study used a measure assessing the development of attitudes and behaviors needed to manage career transitions for an intervention focused on the reconstruction of life story to facilitate clarity and certainty in making a career decision (Savickas, 2011b).

Finally, the results showed a modest increase in career maturity on the one hand and the capacity of mid-adolescents to elaborate reconceptualization and performing change IMs on the other hand. This suggests that these cases could benefit from prolonged interventions to foster career maturity as well as follow-up sessions focused on these types of narrative innovation. Counselor support in these psychological dimensions may promote narrative continuity and coherence, as well as agency in change, thus enabling a deepening and securing of the process of change. These are important practical implications that should be the target of future studies.

\subsubsection{Limitations and possibilities for future research}

By replicating some of the findings of previous studies (Cardoso et al., 2014a, 2014b), this study allowed us to gain further confidence in the results of the studies on process research of LDC obtained so far. As this study only investigated one case, this limits the possibility that these results may be applied to other cases. Based on these results, we believe it is time to explore the specific hypotheses generated from this and from previous studies. In this study, we highlight the role of ambivalence as a potential complicating factor of LDC, as well the role of reconceptualization in developing more substantial changes. The integration of outcome measures in these types of studies to assess meaning construction will provide us with a broader understanding of LDC effectiveness, hopefully helping practitioners implement their interventions.

\section{Acknowledgments}

This study was partially conducted at the Psychology Research Centre, University of Minho, and supported by the Portuguese Foundation for Science and Technology and the Portuguese Ministry of Education and Science through national funds and when applicable co-financed by FEDER under the PT2020 Partnership Agreement (UID/PSI/01662/2013).

This study had also the support of the CICPSI - University of Lisbon.

\section{References}

Alves, D., Mendes, I., Gonçalves, M. M., \& Neimeyer, R. A. (2012). Innovative moments in grief therapy: Reconstructing meaning following perinatal death. Death Studies, 36, 795-818. http://dx.doi.org/10.1080/07481187.2011.608291.

Brown, S. D. (2015). Career intervention efficacy: Making a difference in people's lives. In P. J. Hartung, M. L. Savickas, \& W. B. Walsh (Eds.), Handbook of Career Intervention: Vol. 1 Applications (pp. 61-77). Washington, DC: American Psychological Association.

Bruner, J. (1986). Actual minds, possible worlds. Cambridge, MA: Harvard University Press.

Cardoso, P. (2012). Maladaptive repetition and career construction. Journal of Vocational Behavior, 81, 364-369.

Cardoso, P., Silva, J., Gonçalves, M. M., \& Duarte, M. E. (2014a). Innovative moments in Career Construction Counseling. Journal of Vocational Behavior, 84, 11-20. http:// dx.doi.org/10.1016/j.jvb.2013.10.001.

Cardoso, P., Silva, J., Gonçalves, M. M., \& Duarte, M. E. (2014b). Narrative innovation in Life Design Counseling: The case of Ryan. Journal of Vocational Behavior, 85, 276-286. http://dx.doi.org/10.1016/j.jvb.2014.08.001.

Csikszetmihalyi, M., \& Beattie, O. V. (1979). Life themes: A theoretical and empirical exploration of their origins and effects. Journal of Humanistic Psychology, 19 , $45-63$.

Di Fabio, A., \& Maree, J. G. (2011). Group-based Life Design Counseling in an Italian context. Journal of Vocational Behavior, 80, 100-107.

Erikson, E. H. (1968). Identity: Youth and crisis. New York: Norton.

Gonçalves, O. F. (2000). Viver narrativamente. [To live narratively] Coimbra: Quarteto.

Gonçalves, M. M., \& Ribeiro, A. (2012). Narrative processes of innovation and stability within the dialogical self. In H. J. M. Hermans, \& T. Gieser (Eds.), Handbook of Dialogical Self Theory (pp. 310-318). Cambridge: Cambridge University Press.

Gonçalves, M. M., Matos, M., \& Santos, A. (2009). Narrative therapy and the nature of "innovative moments" in the construction of change. Journal of Constructivist Psychology, 22, 1-23. http://dx.doi.org/10.1080/10720530802500748.

Gonçalves, M. M., Mendes, I., Ribeiro, A. P., Angus, L., \& Greenberg, L. (2010). Innovative moments and change in emotion-focused therapy: The case of Lisa. Journal of Constructivist Psychology, 23, 267-294. http://dx.doi.org/10.1080/10720537.2010.489758.

Gonçalves, M. M., Ribeiro, A., Mendes, I., Matos, M., \& Santos, A. (2011a). Tracking novelties in psychotherapy process research: The Innovative Moments Coding System. Psychotherapy Research, 21, 497-509. 
Gonçalves, M. M., Ribeiro, A. P., Stiles, W. B., Conde, T., Matos, M., Martins, C., et al. (2011b). The role of mutual in-feeding in maintaining problematic self narratives: Exploring one path to therapeutic failure. Psychotherapy Research, 21, 27-40. http://dx.doi.org/10.1080/10503307.2010.507789.

Gonçalves, M. M., Mendes, I., Cruz, G., Ribeiro, A. P., Sousa, I., Angus, L., \& Greenberg, L. (2012). Innovative moments and change in client-centered therapy. Psychotherapy Research, 22, 389-401. http://dx.doi.org/10.1080/10503307.2012.662605.

Gonçalves, M. M., Ribeiro, A. P., Silva, J., Mendes, I., \& Sousa, I. (2016). Narrative innovations predict symptom improvement: Studying innovative moments in narrative therapy of depression. Psychotherapy Research. http://dx.doi.org/10.1080/10503307.2015.1035355 (in press).

Gottfredson, L. S. (2002). Gottfredson's theory of circumscription and compromise. In D. Brown (Eds.), Career choice and development (pp. 85-148) (4th ed.). California, CA: Jossey Bass.

Habermas, T., \& Bluck, S. (2000). Getting a life: The emergence of the life story in adolescence. Psychological Bulletin, 126, 748-769.

Habermas, T., Ehlert-Lerche, S., \& de Silveira, C. (2009). The development of the temporal macrostructure of life narratives across adolescence: Beginnings, linear narrative form, and endings. Journal of Personality, 77, 527-560. http://dx.doi.org/10.1111/j.14676494. 2008.00557.x.

Havighurst, R. J. (1948). Developmental tasks and education. New York: Longman.

Heppner, M. J., \& Hendricks, F. (1995). A process and outcome study examining career indecision and indecisiveness. Journal of Counseling Psychology, 73 , $426-437$.

Hermans, H. J. M., \& Hermans-Jansen, E. (1995). Self-narratives: The construction of meaning in psychotherapy. New York: Guilford.

Hill, C. E., \& Lambert, M. J. (2004). Methodological issues in studying psychotherapy processes and outcomes. In M. J. Lambert (Ed.), Bergin and Garfield's handbook of psychotherapy and behavior change (pp. 84-135) (5th ed.). New York: Wiley.

Holland, J. L. (1997). Making vocational choices: A theory of vocational personalities and work environments (3rd ed.). Odessa, FL: Psychological Assessment Resources.

Jacobson, N. S., \& Truax, P. (1991). Clinical significance: A statistical approach to defining meaningful change in psychotherapy research. Journal of Consulting and Clinical Psychology, 59, 12-19. http://dx.doi.org/10.1037/0022-006X.59.1.12.

Janeiro, I., \& Marques, J. F. (2010). Career coping styles: Differences in career attitudes among secondary school students. International Journal for Educational and Vocational Guidance, 10, 35-48. http://dx.doi.org/10.1007/s10775-009 9170-3.

Janeiro, I. N., Mota, L. P., \& Ribas, A. M. (2014). Effects of two types of career interventions on students with different career coping styles. Journal of Vocational Behavior, $85,115-124$.

Matos, M., Santos, A., Gonçalves, M. M., \& Martins, C. (2009). Innovative moments and change in narrative therapy. Psychotherapy Research, 19, 68-80. http://dx.doi. org/10.1080/10503300802430657.

McAdams, D. P. (1985). Power and intimacy. New York: Guilford Press.

McAdams, D. P. (1993). The stories we live by: Personal myths and the making of the self. New York: William Morrow.

McAdams, D., \& Pals, J. L. (2006). A new big five: Fundamental principles of an Integrative Science of Personality. American Psychologist, 61, 204-217.

Meira, L., Gonçalves, M. M., Salgado, J., \& Cunha, C. (2009). Everyday life change: Contribution to the understanding of daily human change. In M. Todman (Ed.), Selfregulation and social competence: Psychological studies in identity, achievement and work-family dynamics (pp. 145-154). Athens: ATINER.

Mendes, I., Ribeiro, A., Angus, L., Greenberg, L. S., Sousa, I., \& Gonçalves, M. M. (2010). Narrative change in emotion-focused therapy: How is change constructed through the lens of the innovative moments coding system? Psychotherapy Research, 20, 692-701. http://dx.doi.org/10.1080/10503307.2010.514960.

Mendes, I., Ribeiro, A., Angus, L., Greenberg, L. S., Sousa, I., \& Gonçalves, M. M. (2011). Narrative change in emotion-focused psychotherapy: A study on the evolution of reflection and protest innovative moments. Psychotherapy Research, 21, 304-315. http://dx.doi.org/10.1080/10503307.2010.514960.

Refhuss, M. C., Del Corso, J., Glavin, K., \& Wykes, S. (2011). Impact of the Career Style Interview on individuals with career concerns. Journal of Career Assessment, 19, 405-419http://dx.doi.org/10.1177/1069072711409711

Ribeiro, A. P., Ribeiro, E., Loura, J., Gonçalves, M. M., Stiles, W. B., Horvath, A. O., \& Sousa, I. (2014). Therapeutic collaboration and resistance: Describing the nature and quality of the therapeutic relationship within ambivalence events using the Therapeutic Collaboration Coding System. Psychotherapy Research, $346-359$.

Ribeiro, A. P., Gonçalves, M. M., Silva, J. R., Brás, A., \& Sousa, I. (2015). Ambivalence in narrative therapy: A comparison between recovered and unchanged cases. Clinical Psychology E' Psychotherapy. http://dx.doi.org/10.1002/cpp.1945.

Santos, P. J. (2007). Dificuldades de escolhas vocacional. [career decison-making difficulties] Coimbra: Almedina.

Santos, A., Gonçalves, M. M., \& Matos, M. (2011). Innovative moments and poor outcome in narrative therapy. Counselling and Psychotherapy Research, 11, 129-139http://dx.doi.org/10.1080/14733140903398153

Sarbin, T. R. (1986). The narrative and the root metaphor for psychology. In T. R. Sarbin (Ed.), Narrative psychology: The storied nature of human conduct (pp. 3-21). New York: Praeger.

Savickas, M. L. (1995). Examining the personal meaning of inventoried interests during career counselling. Journal of Career Assessment, 3, 188-201.

Savickas, M. L. (2011a). Career counseling. Washington, DC: American Psychological Association.

Savickas, M. L. (2011b). Constructing careers: Actor, agent, and author. Journal of Employment Counseling, 48, 179-181.

Savickas, M. L. (2013). Career construction theory and practice. In R. W. Lent, \& S. D. Brown (Eds.), Career development and counseling: putting theory and research to work (pp. 147-183) (2nd ed.). Hoboken, New Jersey: John Wiley \& Sons.

Savickas, M. L., \& Porfeli, E. J. (2011). Revision of the career maturity inventory: The adaptability form. Journal of Career Assessment, 19(4), 355-374http://dx.doi.org/10. $1177 / 1069072711409342$

Savickas, M. L. (2015). Life-Design Counseling Manual. Vocopher.

Stauffer, S. D., Perdrix, S., Masdonati, J., Massoudi, K., \& Rossier, J. (2013). Influence of clients'personality and individual characteristics on the effectiveness of career counseling intervention. Australian Journal of Career Development, 22, 4-13. http://dx.doi.org/10.1177/1038416213480495.

Westra, H. (2011). Comparing the predictive capacity of observed in-session resistance to self-reported motivation in cognitive behavioral therapy. Behaviour Research and Therapy, 49, 106-113.

Whiston, S. C., \& Rose, C. S. (2015). Career counseling process and outcome. In P. J. Hartung, M. L. Savickas, \& W. B. Walsh (Eds.), APA Handbook of Career Intervention, Vol. 1. (pp. 43-60). Washington, DC: APA Books.

White, M., \& Epston, D. (1990). Narrative means to therapeutic ends. New York: Norton. 